\title{
Cylinder liner deformation orders and efficiency of a piston ring- pack
}

\author{
Erjon Selmani ${ }^{2,{ }^{*}}$,Cristiana Delprete ${ }^{1}$ and Arian Bisha $^{2}$ \\ ${ }^{1}$ Politecnico di Torino, Corso Duca degli Abruzzi 24, 10129 Torino, Italy \\ ${ }^{2}$ Universiteti Politeknik I Tiranes, Sheshi Nene Tereza 1,1001 Tirana, Albania
}

\begin{abstract}
One of the several losses of a combustion chamber is the gas leakage toward the crankcase due to imperfect sealing of the rings. It is commonly known as blow by and it affects efficiency and emissions. The paper initially describes a bibliographic review of the phenomenon, together with the equations of the system. A typical piston ring pack for internal combustion engine is proposed to be analysed and solved using ${ }^{\circ}$ Ricardo RINGPAK Solver. A specific issue such as Bore distortion orders were used to investigate the sealing capacity of the ring-pack in terms of ring dynamics, inter-ring pressures and mass flows. Bore distortion orders and their magnitude showed to affect the ring pack behavior. Order zero distortion resulted to be the most important order due to the highest amount of gas lost in the crankcase, while orders three and four resulted to generate high blow-by values, even if their magnitude of distortion is lower in comparison to other orders.
\end{abstract}

\section{Introduction}

The combustion chamber of an internal combustion engine is desired to be gas tightness, piston rings are the mechanical elements interposed between the piston and the liner to guarantee this requirement. However, their tightness is not perfect and part of the intake gas mixture is lost toward the crankcase, also known as blow-by. In addition, some trapped gas may go back to the combustion chamber during the exhaust stroke and be ejected as unburned hydrocarbons, also known as blowback. Piston rings are designed to seal off the chamber by making continuous contact with the cylinder liner. However, on the cylinder side, the contact is influenced by the lateral force exerted by the ring and by the distortion of the liner. The cylinder bore is subjected to high gas pressures and temperatures as well as bolt forces and piston thrust. Due to these, the cylinder bore is deformed and can affect the contact with the ring face.

\section{Ring dynamics and gas flow}

Piston rings are curved beam with an end gap. Their main function is to seal off the combustion chamber against the crankcase. Due to the gap, the ring acts as a spring and exerts a radial force toward the cylinder liner, necessary to push and hold the ring against the liner. Due to thermal expansion in axial direction, ring axial width is smaller than the groove height. Inter ring dynamics is highly affected by inter ring fluid dynamics and thus, both phenomenon must be studied together. The ring motion with respect to its groove can be subdivided in three directions: axial, radial and twist.

\subsection{Ring axial and radial dynamics, ring twist.}

The main forces acting in the axial direction of the ring cross section are given in Figure 1, while equation (1) describes the mechanical equilibrium of forces in this direction [1].

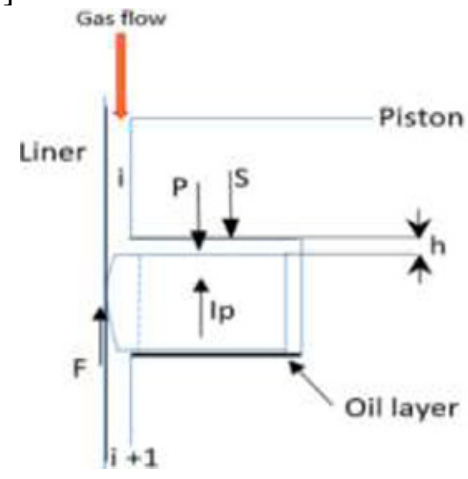

Fig. 1. Forces in axial direction

Where:

$\mathrm{m}_{\mathrm{r}}=$ mass of the ring

$\mathrm{h}=$ ring-groove clearance

$\mathrm{F}_{\mathrm{P}}=$ Force due to gas pressure

$I_{P}=$ force due to inertia

$\mathrm{F}_{\mathrm{F}}=$ Force due to the oil in the ring-liner interface

$F_{S}=$ Force generated from the squeeze of the oil in the groove. 
Piston rings can move radially into the groove, this motion is necessary to account for thermal expansion of the ring, but also to comply with the piston secondary motion, thermal deformation or liner distortion. This motion gives the so-called "conformability" to the cylinder bore, i.e. the capacity to adapt to the bore surface. In Figure 2 are given the main forces acting in the radial direction. When the inward force overcomes the outward one, the ring face lifts-off from the liner, causing a "radial collapse". When this occurs, the quantity of gas escaped between regions suddenly increases. Figure 3 gives the contact between the piston ring and the deformed cylinder bore shape under real working conditions.

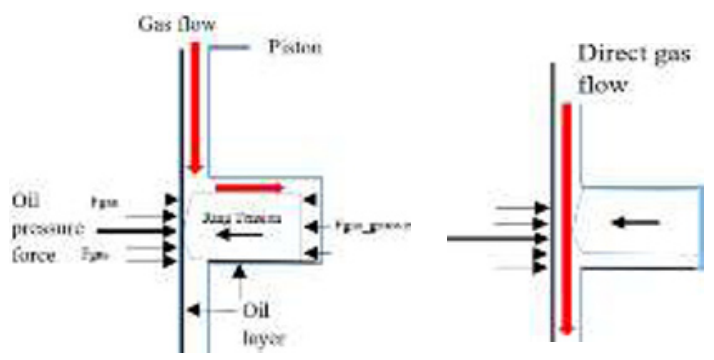

Fig. 2. Forces in radial direction and radial collapse.

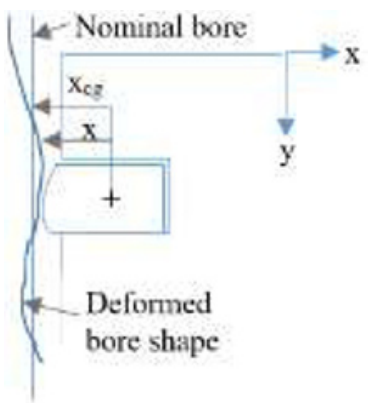

Fig. 3. Ring contact with the deformed bore.

Equation (2) describes the ring motion in the radial direction, according to the forces given in Figure 2.

$$
m_{r} \frac{d^{2} x_{c g}}{d t^{2}}+F_{\text {tension }}+\Delta F_{g a s}-F_{\text {oil }}=0
$$

The cylinder bore, nominally designed to be round and straight, in fact is distorted. This distortion is caused by a large number of factors such as the combustion pressure and temperature, thermal expansion and tightening effect of the cylinder head bolts. It introduces new effects on the radial dynamics with respect to the nominal bore shape. According to Figure 3, we can define the ring center of gravity with reference to relative position, as given in equation (3) below:

$$
x_{c g}=x+\left(x_{c g}-x\right)
$$

The ring radial acceleration can be described as:

$$
a_{r}=\frac{d^{2} x_{c g}}{d t^{2}}=\frac{d^{2} x}{d t^{2}}+\frac{d^{2}\left(x_{c g}-x\right)}{d t^{2}}
$$

The term $\left(x_{c g}-x\right)$ refers to the instantaneous twist angle of the ring, when it is small or when its variation is contained, it can be neglected.
Several research were performed on the the radial dynamics of the piston rings. Dukes in [2] experimentally recorded that collapse occurs when ring lifts from lower to upper groove flank. Tian in [3] and Rabutè et.al. in [4], discovered that radial collapse is sensitive to operating conditions, to the design of ring cross section and to the extent of lubricated area on ring face. Lijima et.al [5] observed the radial collapse of the ring at high speed and with the ring lifted at the upper groove flank. Przesmitzki et.al. [6] had described radial collapse with a more complex behavior of the ring dynamics. They observed that ring rotation promoted oil transport and oil transport blocked the gas flow path between rings and grooves, forcing the inward radial collapse.

The third degree of freedom is the twist of the ring around its circumference axis. Figure 4 at the left shows the positive twist angle $\alpha$ for a ring section and for a straight bore. At the right is depicted a more realistic case, where the effect of the bore distortion was also included.
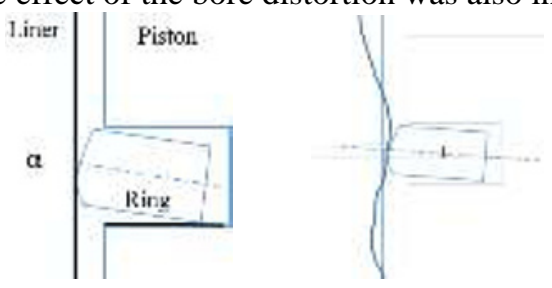

Fig. 4. Ring twist angle.

When the twist angle is considered, the equation of equilibrium must include all the moments acting on the center of the ring section, according to equation (5):

$$
I \frac{d^{2} \alpha}{d t^{2}}+M_{s}+M_{g}+M_{h}=0
$$

Where:

$\mathrm{I}=$ moment of inertia of the ring section

Ms $=$ Torsional moment

$\mathrm{Ms}=\mathrm{kt} * \alpha$

$\mathrm{kt}=$ torsional stiffness of the ring

$\mathrm{Mg}=$ moment due to gas pressure

$\mathrm{Mh}=$ moment due to hydrodynamic action of the lubrication oil

References[3], [7-9] addresses the topic in higher detail.

\subsection{Gas flow model}

The gas flow dynamics is modeled using the ideal gas equation and the continuity law, as described in equation (6) for a single inter-ring volume :

$$
\frac{1}{R T}\left(P \frac{d V}{d t}+V \frac{d P}{d t}\right)=\left(\frac{d m_{\text {in }}}{d t}-\frac{d m_{\text {out }}}{d t}\right)
$$

Furuhama in [10] and Namazian in [1], developed the fluid as fully laminar, isothermal and incompressible. These assumptions will be made also in the following work. Similar models were also developed by Kuo et.al. [11], Keribar et.al. [7], Koszalka [12], Tian [13]. The most important forces are gas pressure and inertia, friction remains almost constant and of low magnitude. The most critical situation is at high speed and low load, where inter ring pressures are lower and inertial force are higher. Under this situation the second ring flutters, increasing the amount of gas escaped in the crankcase. 
Ring lift is not uniform over its circumference and seems to lift initially near the gap. Tian in [3] explains in detail also the phases of the blow back.

\section{Cylinder bore distortion}

In this work, the effect of the bore distortion on the interring dynamics and sealing performances was analysed in higher detail. The bore distortion of a transversal section for a cylinder liner is given in Figure 5, and can be modeled by means of Fourier series according to equation (7)

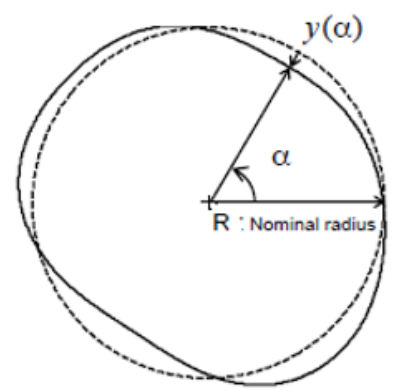

Fig. 5. Bore distortion profile.

$$
y_{\alpha}=A_{0}+\sum_{k=1}^{n} A_{k} \sin \left(k_{\alpha}+\varphi_{k}\right)
$$

Where:

$\alpha=$ position around the circumference

$\mathrm{A}_{\mathrm{k}}$ and $\varphi_{\mathrm{k}}=$ magnitude and phase of the $\mathrm{k}^{\text {th }}$ distortion order

References [14-16] describes the typical and most important distortion orders for a cylinder bore. Order zero corresponds to a uniform expansion of the circumference near the top dead center, due to high temperature and pressure in the combustion chamber. Order one distortion represents a rigid shift of the cylinder axis with respect to the nominal axis. This shift is the result of the deformation between top and bottom part of adiacent cylinders. Order two distortion shows an elliptical deformation shape and arises due to the expansion of the cylinder top part and compression of the cylinder bottom part. Order three distortion shows a three-lobe deformation $(\mathrm{n}=3)$ and is highly influenced by thermal loads. Order four distortion $(n=4)$ shows a typical clover leaf deformed shape, and is highly influenced by the tightening forces exerted by the head bolts on the cylinder block. In general, order zero and order one have larger magnitudes of distortion than orders two to four. Generally speaking, orders $\geq 4$ have shown low magnitude on the distortion of the cylinder, and thus are not analysed. Figure 6 shows the first five distortion orders.
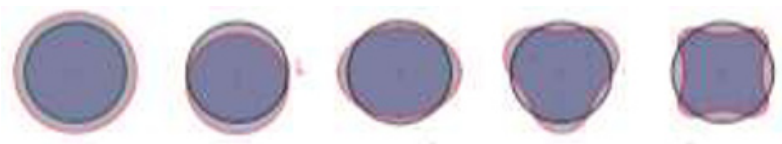

$\mathrm{n}=0$ $n=1$ $n=2$ $n=3$ $n=4$

Fig. 6. Bore distortion orders.

\section{Cylinder analysis}

In the present work the liner was analysed by means of F.E.M to obtain the bore distortion. The cylinder has 120 $\mathrm{mm}$ bore and $148 \mathrm{~mm}$ stroke. The working condition was 2000 r.p.m at full load, with a peak firing pressure of 128 bar. The thrust force exerted by the piston was calculated through a kinematic analysis, meanwhile the force exerted by the tightening bolts was taken as adviced by the engine manufacturer. The distortion orders and phase (Fourier coefficients) have been calculated using Matlab and in figures 7 to 9 are reported the results for various liner locations. Order three and in particular order four, are of 1 or 2 orders of magnitude lower if compared to orders zero or one.
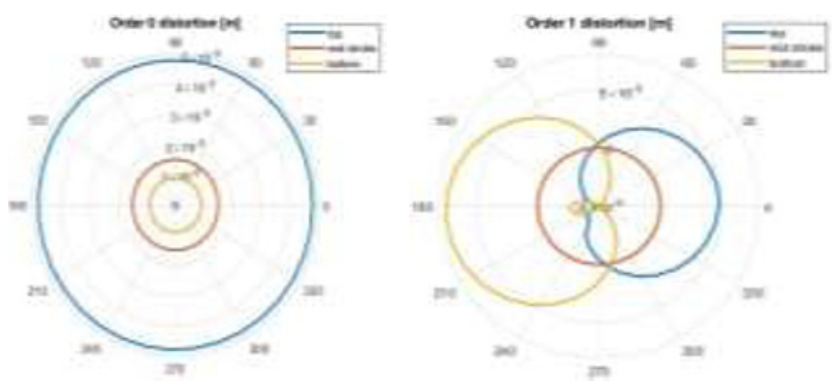

Fig. 7. Order zero (left) and Order one (right) (left).
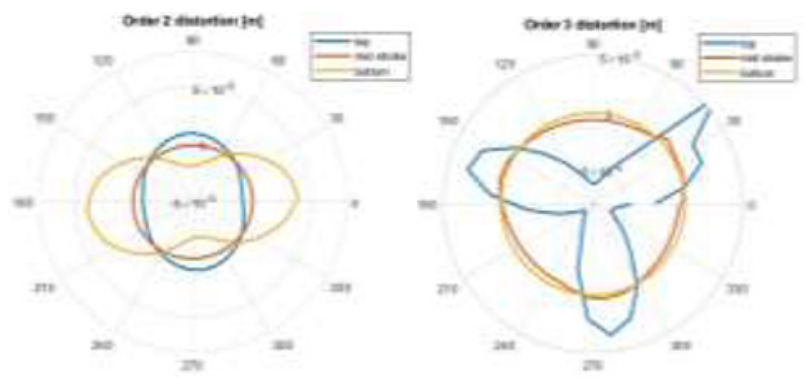

Fig. 8. Order two (left) and three (right).
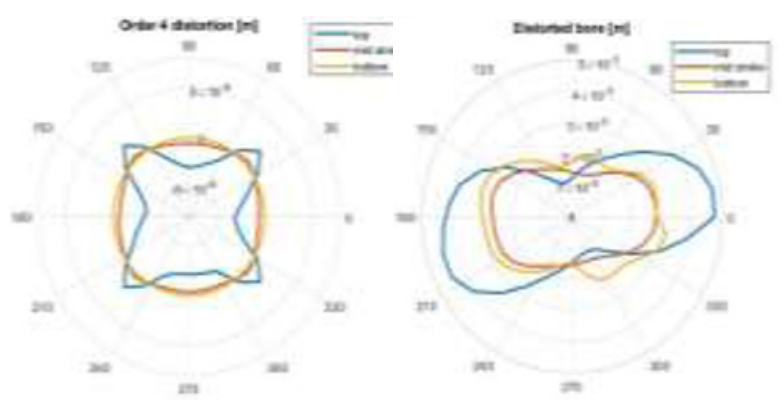

Fig. 9. Order four (left) and five (right).

\section{Simulation}

In reference [17] Authors have proposed a similar analysis but the focus was on other parameters or the engine. In the present work the problem will be extended to the effect of the bore distortion on the ring pack performance. 
In order to investigate it, a set of simulations were performed on the test engine. The simulations were performed considering initially the straight bore (nominal diameter), subsequently was introduced each distortion order as it occurred separately, and at the end the nominal distorted bore. The presented results include the ring dynamics, inter ring gas pressures, ring/liner clearances and the total cumulated blow by for each case under exam.

The engine was a common four cylinder diesel engine, run at the speed of 2000 r.p.m. and full load. For the solution, RINGPAK suite of ${ }^{\circ}$ Ricardo was employed. RINGPAK allows to insert the user defined data through its interface. For the present analysis we selected a 2D axial symmetric model, with rigid components. The bore distortion was inserted as coordinate points while the minimum oil film thickness on the liner wall was inserted equal to $5.3 \mu \mathrm{m}$.

\section{Results and Discussion}

Figures 10 and 11 show the results for the the nondeformed bore.

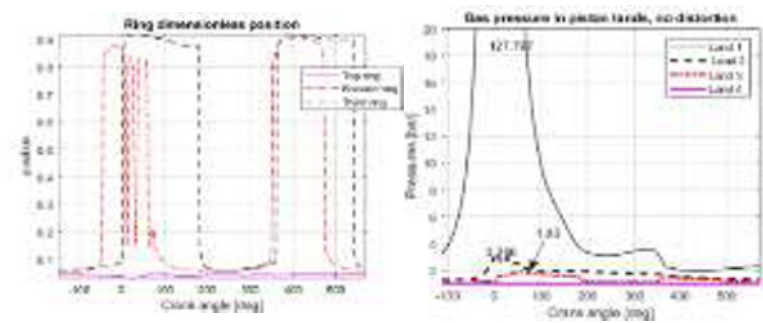

Fig. 10. Ring axial and gas dynamics for non-distorted bore.

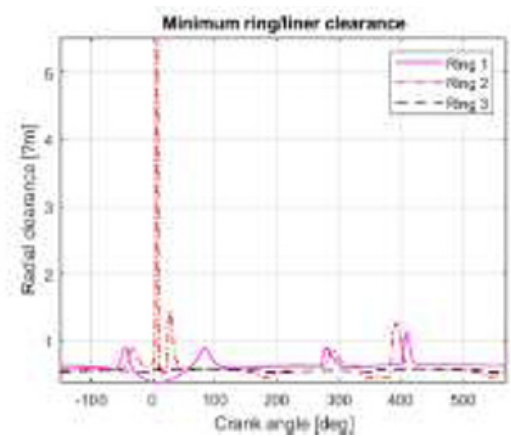

Fig. 11. Ring radial dynamics for non-distorted bore.

In the case of non-distorted bore, top ring remained stable during the entire cycle while second and second ring experienced a motion inside their grooves. This motion was the result of the inertia force and inter-ring pressures. Due to inertia, the second ring lifted by the end of the compression and the start of intake strokes, and fluttered axially during the beginning of the expansion stroke. The third ring lifted only when the piston changed its motion (between the strokes), confirming the dependence by inertia force. According to the gas pressure curves, pressures in the second and third land did not overcome the pressure in the first land, and this is the desired behavior of every ring pack, synonymous of a high sealing capacity. According to the third graph, Figure 11, the second ring shows a radial collapse for a very short crank angle. This behavior, as confirmed by the pressure rise in the third land, gives evidence that when collapse occur, the gas flow suddenly increases.

Figures 12 and 13 show the results of the simulations when the cylinder bore is supposed to be deformed according to order zero distortion pattern.
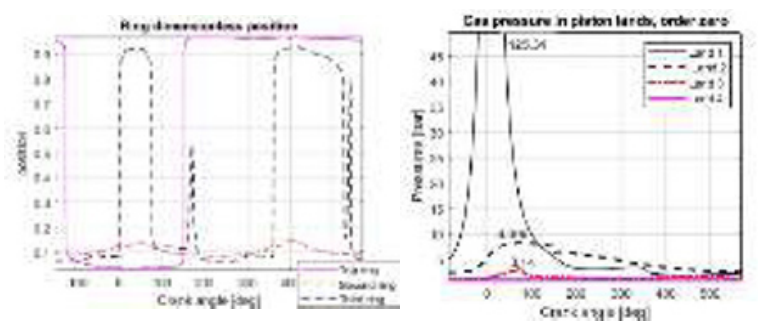

Fig. 12. Ring axial and gas dynamics for order zero distortion

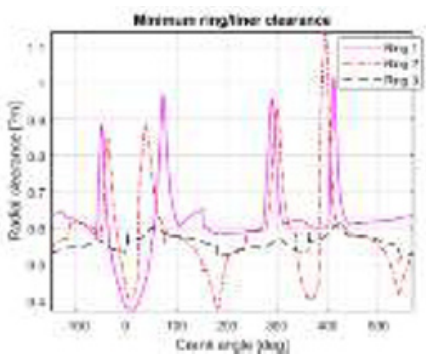

Fig. 13. Ring radial dynamics for order zero distortion.

Order zero distortion makes the cylinder liner to expand near the top dead center and increases almost linearly the bore radius. Top ring will also expand and follow the new bore radius. Under this condition, it is expected that compression ring gaps will increase, allowing larger paths for the gas to flow. This fact is confirmed by the pressure graph, where the second land pressure resulted to be increased, and at approximately 150 degree crank angle after combustion, reached and overcome the top land pressure. The higher pressure in the second land has lifted the top ring up and held the second ring down. A part of the gas in the second land has returned back to the top land and the remaining has flowed in the third land, increasing also the pressure of this region. Surprisingly, none of the rings experienced a radial collapse in this case.

Figures 12 and 13 shows the results of the simulations when the cylinder bore is deformed according to order one distortion pattern.

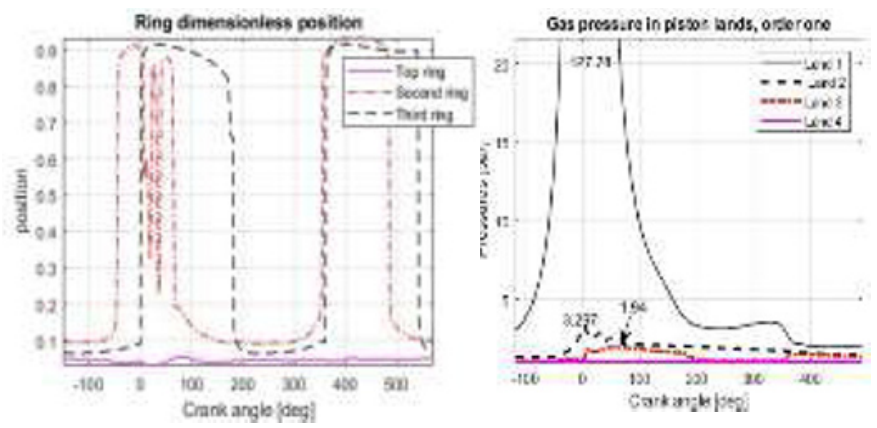

Fig. 14. Ring axial and gas dynamics for order one distortion. 


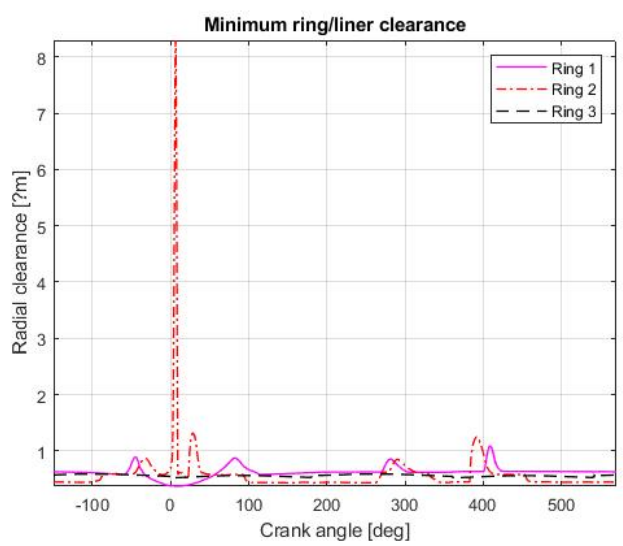

Fig. 15. Ring radial dynamics for order one distortion

Order one distortion represents a rigid shift of the cylinder axis with respect to the cylinder block axis. In this case, the ring dynamics, inter ring pressures and ring/liner clearance are almost similar to the nondistorted case, with exception to the peak pressure values in the lands. The reason for this similarity is linked to the fact that this order represents a linear distortion and not a radial one. In this case, the piston and its rings can follow very well the shape of the cylinder, assuring a high conformability to the liner. According to Figure 15, the second ring undergoes a radial collapse. This behavior is favored by the missing motion of the top ring (relative lift $=0$ ), which blocks the backwards gas flow to the top land. Due to this reason, the high pressure gas pushes the second ring inwards and opens a direct path to flow downwards. Both in this case, and in the non-distorted bore, the radial collapse occurred when the ring is located at the top of the groove, as suggested by experimental results from reference [5].

Figures 16 and 17 shows the results of the simulations when the bore is deformed according to the second order. The second order represents an elliptical shape distortion caused by the expansion of the cylinder block upper part and the compression of the block's lower part. In this case, the behaviour of the system will be not further explained because of its similarity to the order one case, exception made for a slightly higher second land pressure. The low distortion magnitude for this order, together with the good capacity of the ring pack to adapt over it, has made it to perform like the order one distortion.
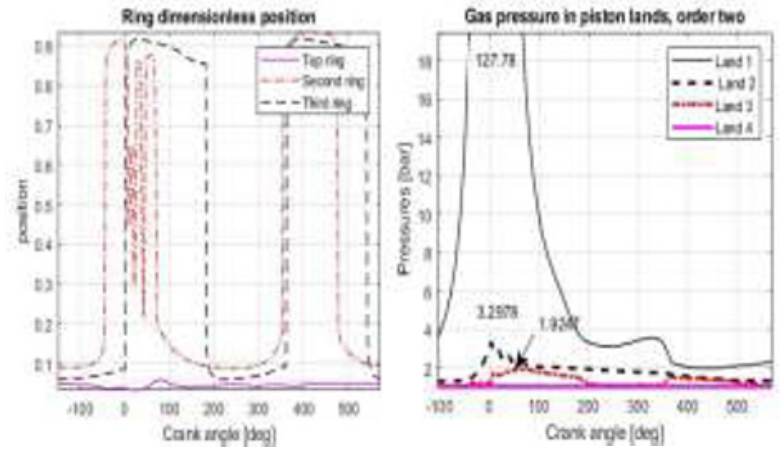

Fig. 16. Ring axial and gas dynamics for order two distortion.

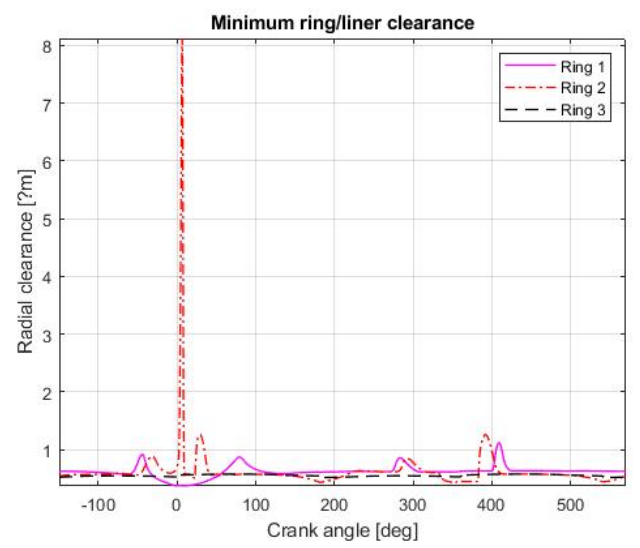

Fig. 17. Ring radial dynamics for order two distortion.

Figure 18 shows the results for order three distortion. According to figure 9, the cylinder bore is reduced both at the top and the bottom of the liner, due to the distortion caused by this order. This distortion will make the rings to conform in a better way with the liner as long as the distortion magnitude is equal or lower to the minimum oil film thickness. At the same time, this distortion will cause a reduction of the ring gaps and improve the gas tightness of the rings.

According to figure 18 , the top ring lifted only at the beginning of the intake stroke and remained seated during the rest of the cycle. Due to this behavior, the top ring could effectively block the gas flow, as confirmed by the pressure curves, which were of very low values during the entire cycle. Only when the top ring lifted, the second land pressure could rise and cross the top land pressure, maintaining a higher value for a short amount of time. It is possible to claim that the top ring lift is only due to inertia force, the same as the second and third rings, which lifted in correspondence of the stroke change. No one of the rings experienced a radial collapse.

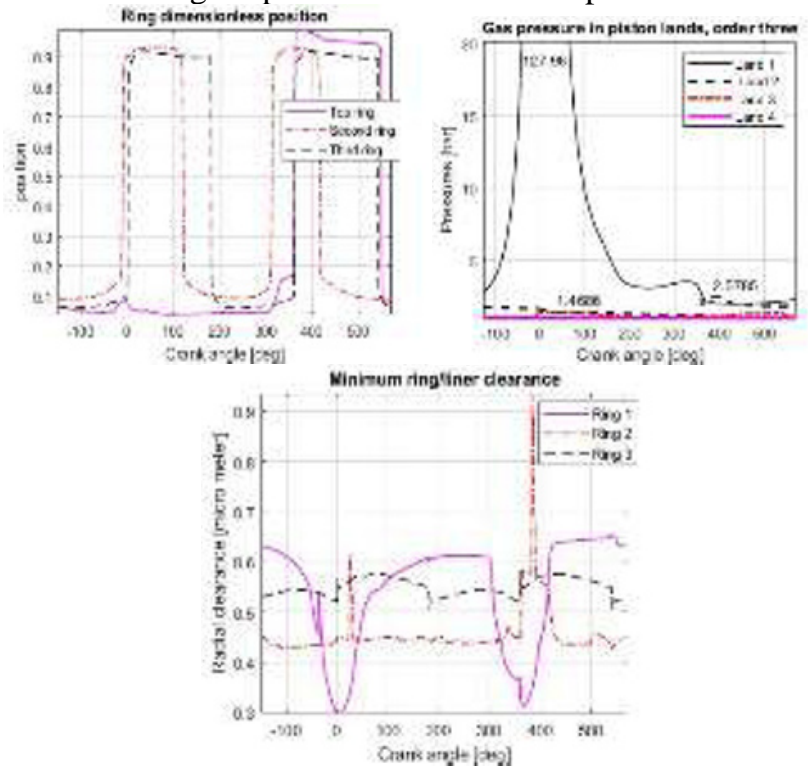

Fig. 18. Results for order three distortion. 

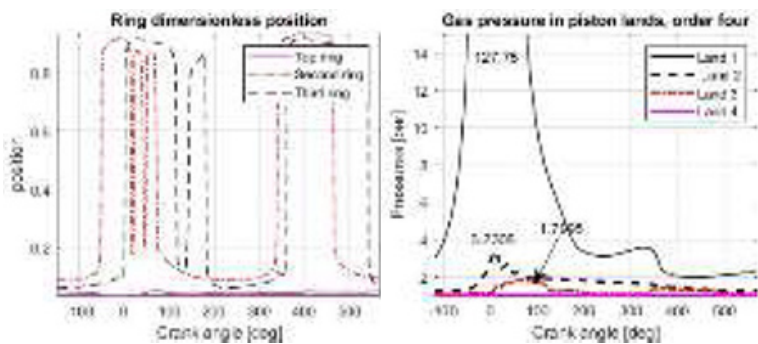

Fig. 19. Ring axial and gas dynamics for order four distortion.

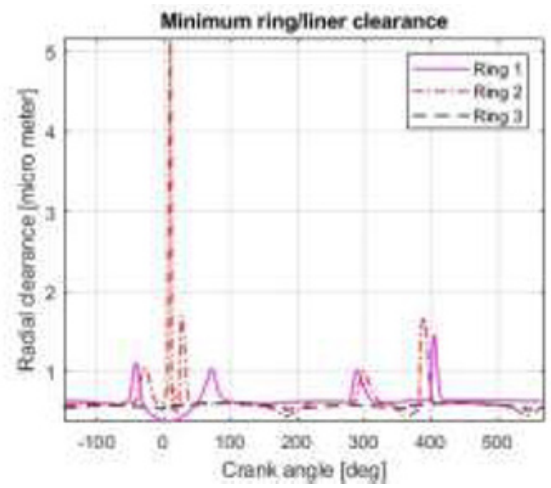

Fig. 20. Ring radial dynamics for order four distortion

Figures 19 and 20 give the results for the order four distortion, which has a magnitude with one or two orders smaller than previous ones. According to results, the top ring remained stable in its lower groove flank, while the second and third ring continuously changed their position in the grooves. Regardless of an optimally located top ring in the groove, this evidence shows that some gas can flow downwards. This behavior is confirmed through the pressure graph, where the second land pressure rises until the radial collapse of the second ring. After this point, the pressure curve in the second land exhibits a sharp fall while the pressure of the third land a slight rise.

Finally, in figures 21 and 22 are depicted the results for the nominal distorted bore, namely the condition where all the distortion orders are included. According to figure22, the top ring stays at the bottom of the groove until the beginning of the exhaust stroke, then it is lifts up the entire exhaust stroke. After a slight fall, it lifts up and doesn't change its position for the entire intake stroke. Each of the motions are caused by different reasons: the first lift is caused by the high pressure gasses in the second land, the second lift is mainly caused by the inertia force but also the gas pressure.
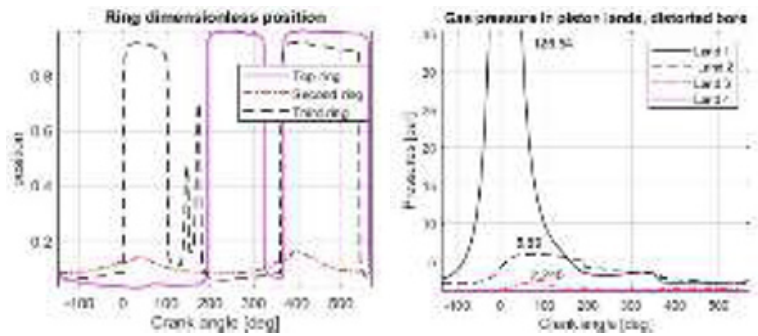

Fig. 21. Ring and gas dynamics for distorted bore.

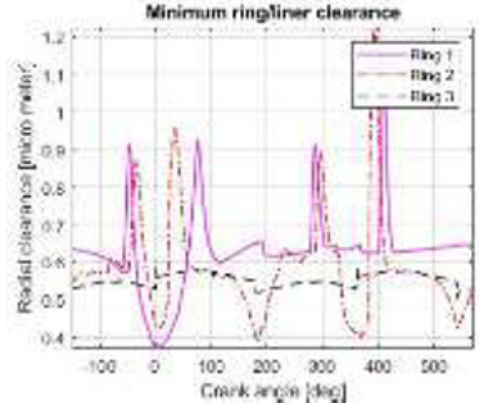

Fig. 22. Ring radial dynamics for the distorted bore.

The second ring is stable at the groove floor for the entire cycle. The third ring exhibits a lift from the combustion until the middle of the expansion stroke, then a light axial flutter and a final lift in correspondence to the intake stroke. Regardless of the high pressures achieved in the several lands, no one of the rings suffered a radial collapse during the cycle.

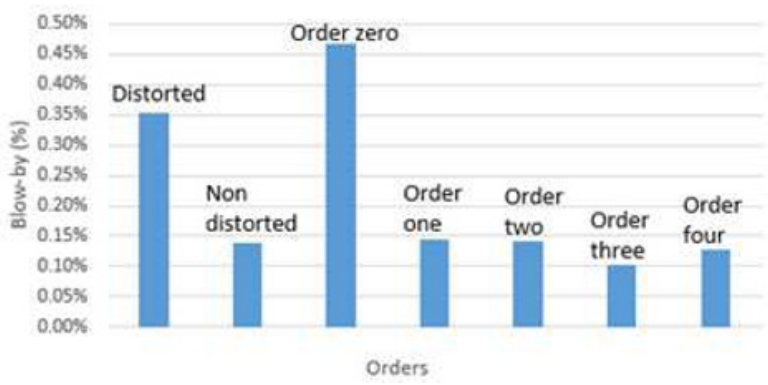

Fig. 23. Blow-by for different distortion orders.

In the following figure 23 are provided the results of the calculations in terms of blow by lost in the crankcase, expressed as percentage of the total cylinder mass. The distorted case expresses the nominal blow-by of the given engine, while the other bars are related to the different orders.

Order zero distortion revealed to be the worst case in terms of sealing capacity for the ring pack. On the other side, orders one to four expressed blow-by values in line with the non-distorted bore profile. The results for order one distortion could be expected, but the result achieved by order two distortion is more optimistic than the expectation, given the shape of bore distortion.

Orders three and four distortion, showed large values of blow by in comparison to the lower magnitude of distortion with respect to other orders. This result may be caused by an over estimation of the forces and moments causing these distortions, but also may be an indication of new flow paths for the gas flow, probably between the ring face and the cylinder liner, which were not investigated in this work.

\section{Conclusion}

The present paper features the tightness analysis of a piston ring-pack under several bore distortion orders. The results, which proved to be in very good correlation with 
the literature, suggests the following important outcome emerged from the discussions:

Bore distortion is a very important factor because it affects the sealing capability of the ring pack in different manner for each order.

Ring axial or radial dynamics are affected from the distortion orders, however, this motion not always explains the amount of gas flowed in the regions.

The highest values of blow by were recorded in the cases where there was no radial collapse of the rings. On the other side, during these cases the top ring moved between the groove flanks while the second ring remained stable during the entire cycle.

Apart from the order three distortion, all the cases with the lowest blow by values had in common the top ring stability and the second ring motion.

The comparison between the blow by for the nondistorted bore (desired result) and the blow by for the distorted bore (real result), can be used as a benchmark for further improvements.

Order zero distortion considerably reduces the ring sealing capability. The high gas pressure and temperature can't be avoided, but the cylinder block should be designed to reduce the magnitude of distortion for this order.

Orders one and two are caused roughly from the same factors, and their results are similar to the nondistorted bore shape. Hence, reducing these factors could double the benefits.

Orders three and four must be studied more carefully. Although they show a lower distortion magnitude, their blow by values are relatively high.

Although the speed of 2000 r.p.m. is a frequent speed of operation, a wider range of speeds should be investigated in order to generate a map of the ring pack behavior.

In this paper only part of the parameters affecting inter-ring dynamics, inter-ring pressures and gas flows has been considered. The analysis can be further extended to other characteristics of the piston ring-pack, nonetheless the results can be used for comparison with other cases, or as a tool for the analysis and design of new components.

\section{References}

1. Namazian, M., and John B. Heywood. Flow in the pistoncylinder-ring crevices of a spark-ignition engine: effect on hydrocarbon emissions, efficiency and power. No. 820088. SAE Technical Paper, 1982.

2. de Dykes, P. K. "Piston Ring Movement during Blow-by in High-Speed Petrol Engines." Proceedings of the Institution of Mechanical Engineers: Automobile Division 1.1 (1947): 71-83.

3. Tian, T. "Dynamic behaviours of piston rings and their practical impact. Part 1: ring flutter and ring collapse and their effects on gas flow and oil transport." Proceedings of the Institution of Mechanical Engineers, Part J: Journal of Engineering Tribology 216.4 (2002): 209-228.

4. Rabutè, Remi, and T. I. A. N. Tian. "Challenges involved in piston top ring designs for modern SI engines." TRANSACTIONS-AMERICAN SOCIETY OF MECHANICAL ENGINEERS JOURNAL OF ENGINEERING FOR GAS TURBINES AND POWER 123.2 (2001): 448-459.

5. Iijima, Naoki, et al. An experimental study on phenomena of piston ring collapse. No. 2002-01-0483. SAE Technical Paper, 2002.

6. S. Przesmitzki and Tian Tian. An Experimental Study of the Time Scales and Controlling Factors Affecting Drastic Blow-by Increases during Transient Load Changes in SI Engines, SAE Paper 2008-01-0794

7. Keribar, Rifat, Zafer Dursunkaya, and Michael F Flemming. "An integrated model of ring pack performance." ASME, Transactions, Journal of Engineering for Gas Turbines and Power 113 (1991): 382389.

8. Ruddy, B.L., Parsons, B., Dowson, D., and Economou, P. N., 1979b, "The Influence of Thermal Distortion and Wear of Piston Ring Grooves Upon the Lubrication of Piston Rings in Diesel Engines," Proceedings of the 6th Leeds-Lyon Symposium on Tribology, ASME, NY.

9. Richardson, D. E. Comparison of measured and theoretical inter-ring gas pressure on a diesel engine. No. 961909. SAE Technical Paper, 1996

10. Furuhama, Shoichi, and T. A. D. A. Tosio. "On the flow of gas through the piston-rings: 2nd Report, The character of gas leakage." Bulletin of JSME 4.16 (1961): 691-698.

11. Kuo, Tang-wei, et al. Calculation of flow in the pistoncylinder-ring crevices of a homogeneous-charge engine and comparison with experiment. No. 890838. SAE Technical Paper, 1989.

12. Koszałka, G. "Modelling the blowby in internal combustion engine. Part I. A mathematical model." Archive of Mechanical Engineering 51.2 (2004): 245-257.

13. Tian, T., et al. "Modeling piston-ring dynamics, blowby, and ring-twist effects." TRANSACTIONS-AMERICAN SOCIETY OF MECHANICAL ENGINEERS JOURNAL OF ENGINEERING FOR GAS TURBINES AND POWER 120 (1998): 843-854.

14. V. V. Dunaevsky (1990) Analysis of Distortions of Cylinders and Conformability of Piston Rings, Tribology Transactions, $\quad 33: 1, \quad 33-40, \quad$ DOI: 10.1080/10402009008981927

15. M. Hennessy \& G. C. Barber (1995) The Effects of Cylinder Wall Surface Roughness and Bore Distortion on Blow-by in Automotive Engines, Tribology Transactions, 38:4, 966-972, DOI: 10.1080/10402009508983494

16. Maassen, Franz, et al. Analytical and empirical methods for optimization of cylinder liner bore distortion. No. 2001-01-0569. SAE technical paper, 2001.

17. Delprete, Cristiana, Arian Bisha, and Erjon Selmani. "Gas Escape from Combustion Chamber to Crankcase, Analysis of a Set of Parameters Affecting the Blow by." International Conference "New Technologies, Development and Applications". Springer, Cham, 2018. 